University of Wollongong

Research Online

Faculty of Engineering - Papers (Archive)

Faculty of Engineering and Information

Sciences

2008

\title{
Management of Voltage Unbalance Through Allocation of Emission Limits to Installations
}

Prabodha Paranavithana

University of Wollongong, ptp123@uow.edu.au

Sarath Perera

University of Wollongong, sarath@uow.edu.au

Danny Soetanto

University of Wollongong, soetanto@uow.edu.au

Follow this and additional works at: https://ro.uow.edu.au/engpapers

Part of the Engineering Commons

https://ro.uow.edu.au/engpapers/5396

\section{Recommended Citation}

Paranavithana, Prabodha; Perera, Sarath; and Soetanto, Danny: Management of Voltage Unbalance Through Allocation of Emission Limits to Installations 2008.

https://ro.uow.edu.au/engpapers/5396

Research Online is the open access institutional repository for the University of Wollongong. For further information contact the UOW Library: research-pubs@uow.edu.au 


\title{
Management of Voltage Unbalance Through Allocation of Emission Limits to Installations
}

\author{
Prabodha Paranavithana, Sarath Perera, Danny Sutanto \\ Integral Energy Power Quality and Reliability Centre \\ School of Electrical, Computer and Telecommunications Engineering \\ University of Wollongong, NSW 2522, Wollongong, Australia.
}

\begin{abstract}
The International Electrotechnical Commission (IEC) has recently released the Technical Report IEC/TR 610003-13 for the assessment of voltage unbalance emission by installations connected to MV, HV and EHV power systems, which is expected to provide the basis for developing a compatible Australian Standard. The philosophy of the approach described in this report is similar to the IEC recommendations for harmonics and flicker allocation. In addition, this involves a unique aspect, the contribution to global voltage unbalance by system inherent asymmetries, noting the fact that the voltage unbalance at a busbar can arise due to both load and system (essentially lines) asymmetries. Although the concepts and the basic principles used in this approach are widely accepted, the Technical Report IEC/TR 61000-3-13 is seen to require further refinements and original developments in relation to some of the key aspects. This paper reports, in summary, the work that has been carried out addressing: (a) propagation of voltage unbalance from MV to LV levels, and (b) global emission in MV systems due to line asymmetries, with the view to make contributions for further improving the present technical report.
\end{abstract}

\section{INTRODUCTION}

Presence of voltage unbalance in electricity transmission and distribution networks in Australia has continued to be a power quality problem of concern. Although there are applicable voltage unbalance regulatory codes such as the National Electricity Code (NEC) [1] and the Electricity Distribution Code (EDC) [2], some network service providers [3], [4] are facing difficulties in complying with the stipulated levels. The NEC specifies that the voltage unbalance be limited at $0.5 \%$ for systems operating at or above $100 \mathrm{kV}, 1.3 \%$ for systems operating between $10 \mathrm{kV}$ and $100 \mathrm{kV}$ and $2.0 \%$ for $10 \mathrm{kV}$ and lower voltage systems when determined over a 30 minute averaging period. According to the EDC, a distributor is obliged to limit the negative sequence voltage at the point of common coupling to a customer's three-phase electrical installation $\leq 1 \%$ allowing excursions up to $2 \%$ for a total of 5 minutes in every 30-minute period.

Recent release of the IEC Technical Report IEC/TR 610003-13 [5] which provides guiding principles for co-ordinating the negative sequence voltage unbalance between various voltage levels of a power system through allocation of emission limits to unbalanced installations can be noted as a means for managing the problem. As in the case of the counterpart Australian Standards for harmonics (AS/NZS 61000-3-6 [6] which is based on IEC/TR 61000-3-6 [7]) and flicker (AS/NZS 61000-3-7 [8] which is based on IEC/TR 61000-3-7 [9]) allocation, this report is expected to provide the basis for developing a compatible Australian Standard.

The concepts and the basic principles used in this technical report, which are similar, however with appropriate modifications, to those in the counterpart IEC Technical Reports for harmonics and flicker allocation, are summarised in Sections II and III respectively. Some of the key aspects, including the propagation of voltage unbalance and the emission arising due to system inherent asymmetries, involved with the recommended voltage unbalance allocation approach have been seen to require further development. Sections IV and V of this paper addresses the MV to LV unbalance propagation and the global contribution to MV unbalance from line asymmetries respectively proposing improved methodologies for their evaluation. Conclusions are given in Section VI.

\section{BASIC CONCEPTS USED IN IEC/TR 61000-3-13}

Emission limits for individual equipment or a customer's installation have been developed based on the impact that these emissions will have on the quality of the voltage. It is important to note that IEC/TR 61000-3-13 addresses the allocation of emission limits only to three-phase installations (distribution of single-phase and dual-phase installations evenly across the three-phases have been considered as a responsibility of the system operator). The following concepts have been used to coordinate the emission with the voltage quality objectives.

\section{A. Compatibility levels}

Compatibility levels are taken as reference values for coordinating the emission and the immunity of equipment or installations which are part of, or supplied by, a supply system in order to ensure the electromagnetic compatibility (EMC) in the whole system. These are generally based on $95 \%$ probability levels of the entire system, using distributions which represent both time and space variations of the disturbance. The IEC defines the voltage unbalance compatibility levels for $\mathrm{LV}$ and MV power systems as $2 \%$, with excursions up to $3 \%$ in some areas where predominantly single-phase loads are connected.

\section{B. Planning levels}

Planning levels, considering them as "internal" quality objectives of the system operator, are taken to facilitate the coordination of the voltage unbalance levels between different 
voltage levels. They can be equal to or lower than the compatibility levels. Planning levels may differ from case to case depending on system structure and circumstances. Indicative planning levels for MV, $\mathrm{HV}$ and EHV voltage levels are given in the Technical Report IEC/TR 61000-3-13 as reproduced in Table II. These are based on the compatibility levels at MV and on existing HV-EHV practices, and consider the need to provide margins between $\mathrm{LV}, \mathrm{MV}$ and HV-EHV for the purpose of the overall EMC co-ordination. The results of an international survey on which these were based are reported on in [10].

TABLE I

INDICATIVE PLANNING LEVELS

\begin{tabular}{c||c|c|c}
\hline Voltage level & MV & HV & EHV \\
\hline Planning level & 1.8 & 1.4 & 0.8 \\
\hline
\end{tabular}

\section{Emission levels}

Emission level from an unbalanced installation into a power system is defined as the magnitude of the unbalanced voltage vector which the considered installation gives rise to at the point of evaluation. This is illustrated by the vector $U_{i}$ in Fig. 1.

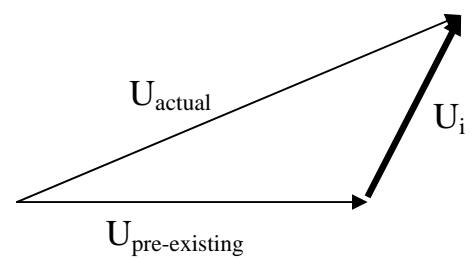

Fig. 1. Emission level, as defined in IEC/TR 61000-3-13, from an unbalanced installation

\section{Assessment methods}

Methods and indices for assessing measured data against the planning levels have been proposed. The recommended indices are characterised by their time integration interval (eg. measured over 10-minutes intervals) and a statistical value, percentile value over the observation period (eg. 95\% weekly values), to be used for the comparison against the planning level. As the proposed co-ordination approach relies on the individual emission limits being derived from the planning levels, it has been recommended that the same indices be applied when assessing the emission levels $\left(\left|U_{i}\right|\right)$ against the corresponding emission limits, and when assessing the actual voltage unbalance levels ( $\left.\left|U_{\text {actual }}\right|\right)$ against the planning levels.

\section{BASIC PRINCIPLES USED IN IEC/TR 61000-3-13}

With the objective of limiting the resultant emission level which arise due to numerous sources of unbalance at or below any point of a system at the set planning level, the following basic principles have been used in assigning emission limits to individual customers in a consistent manner.

\section{A. Summation of emission from numerous sources of unbal-} ance

Generally, the resultant voltage unbalance vector at a point of a system which arise due to various sources of unbalance is the vector addition of the voltage unbalance caused by individual sources at the considered point. Based on this and on the experience, a summation law has been adopted as:

$$
U^{x}=\sqrt[\alpha]{\sum\left(U_{i}^{x}\right)^{\alpha}}
$$

where,

$U^{x}$ - resultant emission level at any busbar $x$

$U_{i}^{x}$ - emission level caused by any three-phase unbalanced installation $i$ on its own at busbar $x$

$\alpha$ - summation law exponent

The exponent $\alpha$ depends upon: (a) type of sources of unbalance, (b) chosen value of probability for the actual voltage unbalance level not to exceed the calculated value, and (c) degree to which individual unbalanced sources vary randomly in magnitude and phase. An indicative value for $\alpha$ is provided in IEC/TR 61000-3-13 as 1.4.

\section{B. Allowed global contribution}

The principle recommended for determining the allowed global contribution to voltage unbalance in a sub-system is illustrated in relation to an MV system in Fig. 2. The resultant voltage unbalance at the MV busbar is determined by the emission from all global sources of unbalance (eg. unbalanced installations connected at the MV $\left(S_{m v}\right)$ and $\mathrm{LV}$ $\left(S_{l v}\right)$ busbars), and also the voltage unbalance that propagates from the upstream (US) HV system. By applying the summation law while restricting the emission levels at the US and MV busbars at the corresponding planning levels, the allowed global contribution to $\mathrm{MV}$ unbalance $\left(U_{G_{m v}}\right)$ can be established as:

$$
U_{G_{m v}}=\sqrt[\alpha]{\left(L_{m v}\right)^{\alpha}-\left(T_{u s-m v} L_{u s}\right)^{\alpha}}
$$

where,

$L_{u s}, L_{m v}$ - planning levels of the US and MV systems respectively

$T_{u s-m v}$ - voltage unbalance transfer coefficient from the US to MV systems

\section{Allocation of allowed global contribution to busbars}

The allowed global contribution $U_{G_{m v}}$ is to be apportioned to various busbars (say, $U_{G_{m v}}^{x}$ for any busbar $x$ ) of the considered MV system according to the total power available for voltage unbalance allocation at the busbar $\left(S^{x}\right)$ with respect to the total available power of the system reflected at the busbar $\left(S_{\text {sys }}^{x}\right)$ as:

$$
U_{G_{m v}}^{x}=U_{G_{m v}} \sqrt[\alpha]{\frac{S^{x}}{S_{s y s}^{x}}}
$$

The power $S_{\text {sys }}^{x}$ is evaluated taking into account the voltage unbalance contributions from neighboring busbars (say, 


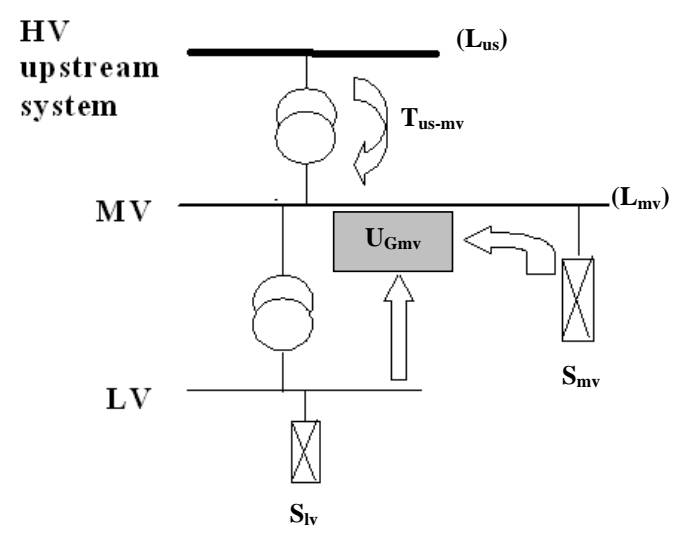

Fig. 2. Simple illustration of determination of allowed global contribution [5]

$1,2, \ldots, n)$ in terms of influence coefficients as:

$S_{\text {sys }}^{x}=k^{1-x} S^{1}+k^{2-x} S^{2}+\ldots+S^{x}+\ldots+k^{i-x} S^{i}+\ldots+k^{n-x} S^{n}$

where, $k^{i-x}$ - voltage unbalance influence coefficient between busbars $i$ and $x$ (ie. voltage unbalance caused at busbar $x$ when $1 p u$ of negative sequence voltage is applied at busbar $i$ ).

\section{Allocation of emission limits to individual installations}

In relation to harmonics and flicker, the total $U_{G_{m v}}^{x}$ is apportioned to individual customers according to their agreed apparent power with respect to the total power at the busbar. However, in the case of voltage unbalance the global emission at a busbar $x$ is generally caused not only by unbalanced installations, but also by system inherent asymmetries. That is:

$$
\left(U_{G_{m v}}^{x}\right)^{\alpha}=\left(U_{\text {loads }}^{x}\right)^{\alpha}+\left(U_{\text {lines }}^{x}\right)^{\alpha}
$$

where, $U_{\text {loads }}^{x}$ and $U_{\text {lines }}^{x}$ are the voltage unbalance emissions caused individually by unbalanced installations (connected at MV and LV levels) and asymmetrical lines (basically MV lines as the contribution from LV feeders can be reasonably ignored) respectively at busbar $x$. Hence, the allocation of the total allowed $U_{G_{m v}}^{x}$ to installations may result in excessive voltage unbalance levels. This has been addressed in IEC/TR 61000-3-13 by introducing a factor named ' $K u e$ ' as defined by (6) which represents the fraction of the allowed $U_{G_{m v}}^{x}$ that can be allocated to unbalanced installations. Conversely, $K^{\prime} u e=1-K u e$ as given by (7) represents the fraction that accounts for system inherent asymmetries contributing to the global voltage unbalance. It has been recommended that Kue or $K^{\prime} u e$ be determined by the system operators considering prevailing system conditions.

$$
\begin{aligned}
K u e^{x} & =\left(\frac{U_{\text {loads }}^{x}}{U_{G_{m v}}^{x}}\right)^{\alpha} \\
K^{\prime} u e^{x} & =\left(\frac{U_{\text {lines }}^{x}}{U_{G_{m v}}^{x}}\right)^{\alpha}
\end{aligned}
$$

The allowed $U_{G_{m v}}^{x}$ is then apportioned to individual customers as:

$$
E_{j}^{x}=\sqrt[\alpha]{K u e^{x}} U_{G_{m v}}^{x} \sqrt[\alpha]{\frac{S_{j}^{x}}{S^{x}}}
$$

where,

$E_{j}^{x}$ - voltage unbalance emission limit of customer installation $j$ supplied by busbar $x$ $S_{j}^{x}$ - agreed apparent power of customer installation $j$

\section{MV to LV Voltage Unbalance Propagation}

The Technical Report IEC/TR 61000-3-13 gives a method for evaluating the MV to LV voltage unbalance transfer coefficient $\left(T_{m v-l v}=\frac{V U F_{l v}}{V U F_{m v}}\right)$ as:

$$
T_{m v-l v} \approx \frac{1}{1+k_{m}\left(\frac{k_{s}-1}{k_{s c}+1}\right)}
$$

where,

$V U F_{l v}, V U F_{m v}$ - voltage unbalance factors (VUF) at the $\mathrm{LV}$ and MV busbars respectively

$k_{m}$ - ratio between the rated motor load (in MVA) and the total load (in MVA) supplied by the LV system

$k_{s}$ - ratio between the positive and the negative sequence impedances of the motor load supplied by the LV system (typically, $5<k_{s}<7$ )

$k_{s c}$ - ratio between the LV short circuit level (in MVA) and the total load (in MVA) supplied by the LV system (a range for $k_{s c}$, covering most of practical systems, between 10 eg. fully loaded 10MVA transformers with $10 \%$ impedance and 25 - eg. fully loaded 400kVA transformers with $4 \%$ impedance, can be considered)

This suggests a value less than unity for $T_{m v-l v}$ in the presence of industrial load bases containing large proportions of mains connected three-phase induction motors (IM), and unity in relation passive loads in general. Although, $T_{m v-l v}=1$ is mathematically trivial for constant impedance (Z) loads, its validity has not been cautiously examined in relation to constant power (PQ) and constant current (I) loads which would exhibit different behaviours under unbalanced supply conditions. As an example, Fig. 3 illustrates the variation of $T_{m v-l v}$ with $k_{s c}$ established using unbalanced load flow analysis [3] when the LV system supplies a load base primarily having constant power elements with 0.9 lagging power factor, compared against unity as applicable to constant impedance loads.

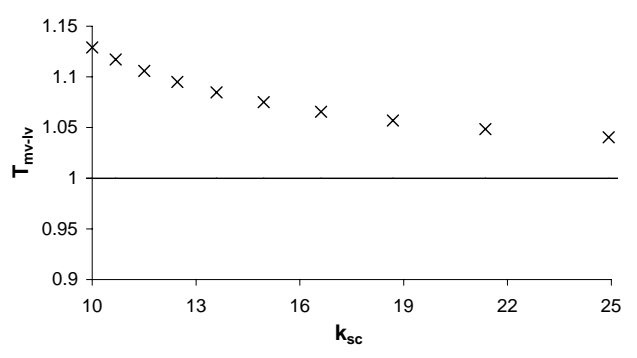

Fig. 3. Variation of $T_{m v-l v}$ with $k_{s c}$ in relation to a load base containing constant power elements with 0.9 lag. pf

Suitable theoretical basis in order to comprehend the influence of the behaviours exhibited by various load types 
under unbalanced supply conditions on the propagation of voltage unbalance from MV to LV levels is initially established using the basics through simplifications and unbalanced load flow analysis. Employing this knowledge, analytical and argumentative manner, an improved and generalised method for estimating $T_{m v-l v}$ is developed as:

$$
T_{m v-l v} \approx \frac{\left|1+j \frac{1}{k_{s c}} \angle \theta_{p f}\right|}{\left(1+\frac{k_{m} k_{s}}{k_{s c}}\right)\left|1+j \frac{k_{z}}{k_{s c}} \angle \theta_{p f: z}\right|\left|1+j \frac{k_{p q}}{k_{s c}} \angle \theta_{p f: p q}\right|^{\beta}}
$$

where,

$k_{z}, k_{p q}$ - ratios of constant impedance and constant power loads (in MVA) to the total load (in MVA) supplied by the LV busbar respectively

$\theta_{p f}, \theta_{p f: z}, \theta_{p f: p q}$ - power factor angles of the total load, constant impedance and constant power loads supplied by the LV system respectively

$\beta \approx-1$ and -2 for low $(\sim 0.9)$ and high $(\sim 1)$ lagging pf conditions respectively

Figs. 4 and 5 illustrate the variation of $T_{m v-l v}$ with $k_{s c}$ in relation to two load bases: (a) Z-10\%, I-5\%, PQ-15\%, IM$70 \%\left(k_{s}=6.7\right)$ and (b) Z-25\%, I-5\%, PQ-60\%, IM-10\% $\left(k_{s}=6.7\right)$ respectively. A lagging pf of 0.9 is assumed for all load components. These show the variations established using (9), (10) and unbalanced load flow analysis. These results indicate that although the expression given by (9) is accurate in relation to a load base containing a large proportion of induction motors, the associated error is greater for a load base dominated by passive elements. Further, Figs. 4 and 5 support (10) as an improved expression for estimating the transfer coefficient $T_{m v-l v}$.

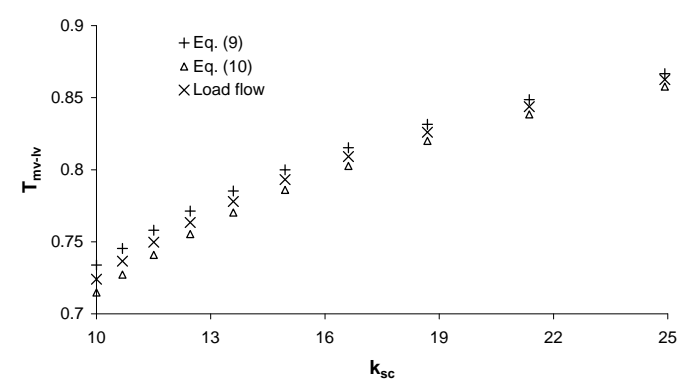

Fig. 4. Variation of $T_{m v-l v}$ with $k_{s c}$ in relation to a load base with Z-10\%, $\mathrm{I}-5 \%, \mathrm{PQ}-15 \%$ and IM-70\%

Figs. 6 (a) and (b) illustrate the variation of $T_{m v-l v}$ (derived using (10)) with $k_{m}=1-k_{p q}$ (related to load bases containing $\mathrm{IM}$ and $\mathrm{PQ}$ ) and $k_{m}=1-k_{z}$ (related to load bases containing IM and Z) respectively. Two cases where $k_{s c} \approx 25$ (representing the maximum) and $k_{s c} \approx 10$ (representing the minimum), a lagging pf factor of 0.9 for all load components and $k_{s}=6.7$ for induction motors are considered. These demonstrate that the transfer coefficient $T_{m v-l v}$ can typically vary in a range: $1.1<T_{m v-l v}<0.6$ depending on the prevailing system and load characteristics.

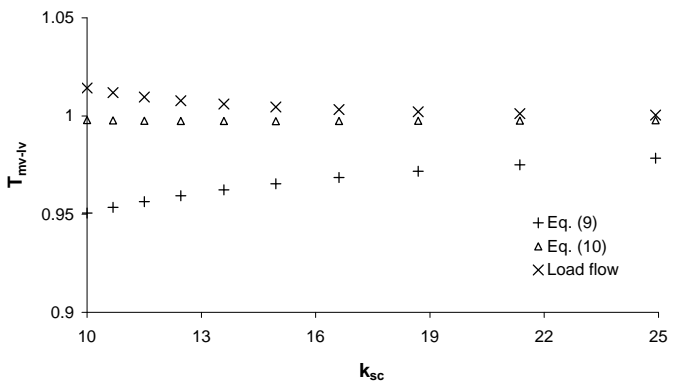

Fig. 5. Variation of $T_{m v-l v}$ with $k_{s c}$ in relation to a load base with Z-25\%, I-5\%, PQ-60\% and IM-10\%

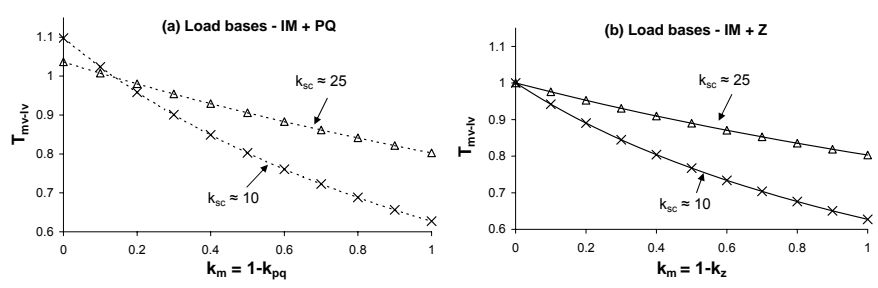

Fig. 6. Variation of $T_{m v-l v}$ (a) with $k_{m}=1-k_{p q}$ (b) with $k_{m}=1-k_{z}$, for two cases where $k_{s c} \approx 25$ and $k_{s c} \approx 10$

\section{Global Contribution to MV Unbalance From LINE ASYMMETRIES}

The IEC Technical Report IEC/TR 61000-3-13 indicates a direction as given by (11) for assessing the contribution to voltage unbalance from a radial asymmetrical line at its receiving end, together with a set of indicative values for the factor Kue as reproduced in Table V.

$$
U_{t}^{r e c .} \approx \frac{\left|Z_{-+: t} I_{+: t}\right|}{V_{n-p}}
$$

where,

$U_{t}^{\text {rec. }}$ - voltage unbalance contribution (as a VUF) by an asymmetrical line $t$ at its receiving end

$Z_{-+: t}$ - coupling impedance between negative and positive sequence networks of line $t$

$I_{+: t}$ - positive sequence current in line $t$

$V_{n-p}$ - nominal phase-to-phase voltage of the system

It has been seen that the accuracy of (11) is acceptable in the presence of passive loads (eg. PQ) [4]. However, its validity is questionable especially in relation to an asymmetrical MV line supplying an industrial load base containing a large proportion of three-phase induction motors, owing to relatively high levels of negative sequence current drawn by induction motors in the presence of voltage unbalance.

To develop a comprehensive theoretical basis on the influence of line asymmetries on the global voltage unbalance in MV power systems and its dependency on various load types, studies are carried out in relation to a radial system. The considered power system is shown in Fig. 7 where the negative sequence voltage at busbar $\mathrm{MV}\left(V_{-t}^{m v}\right)$ which arise 
TABLE II

INDICATIVE RANGE OF VALUES FOR $K u e$

\begin{tabular}{l|c}
\hline System characteristics & $K u e$ \\
\hline \hline - Highly meshed system with generation locally connected near load centers & \\
- Transmission lines fully transposed, otherwise lines are very short (few km) & $0.8-0.9$ \\
- Distribution systems supplying high density load area with short lines or cables & \\
\hline - Mix of meshed system with some radial lines either fully or partly transposed & $0.6-0.8$ \\
- Mix of local and remote generation with some long lines & \\
- Distribution systems supplying a mix of high density and suburban area with relatively short lines $(<10 \mathrm{~km})$ & \\
\hline - Long transmission lines generally transposed, generation mostly remote & $0.5-0.6$ \\
- Generally radial sub-transmission lines partly transposed or un-transposed & \\
- Distribution systems supplying a mix of medium and low density load area with relatively long lines $(>20 \mathrm{~km})$ & \\
- three-phase motors account for only a small part of the peak load (eg. 10\%) & \\
\hline
\end{tabular}

as a result of the asymmetrical MV line $t$ can be written employing sequence components as:

$$
V_{-t}^{m v}=-\left(Z_{-+: t} I_{+: t}+Z_{++: t} I_{-: t / t}\right)
$$

where,

$Z_{++: t}$ - positive sequence impedance of line $t$

$I_{-: t / t}$ - negative sequence current in line $t$ which arises as a result of line $t$ itself

\section{Passive loads:}

The magnitude of the negative sequence voltage $V_{-t}^{m v}$ in the presence of various types of passive loads can be established as:

$$
\left|V_{-t}^{m v}\right| \approx\left|Z_{-+: t} I_{+: t}\right|\left(1-V R_{t}\right)^{\gamma}
$$

where,

$V R_{t}=\left|\frac{Z_{++: t} I_{+: t}}{V_{+}^{m v^{\prime}}}\right|$, the voltage regulation of line $\mathrm{t}$

$V_{+}^{m v^{\prime}}$ - positive sequence voltage at busbar $M V^{\prime}$

$\gamma= \begin{cases}1 & \text { for Z loads } \\ 0 & \text { for I loads } \\ -1 & \text { for PQ loads with low lag. pf (eg. 0.9) } \\ -2 & \text { for PQ loads with high lag. pf (eg. 1) }\end{cases}$

Considering most practical circumstances where $V R_{t}<10 \%$, the factor $\left(1-V R_{t}\right)^{\gamma}$ can be approximated to unity. Hence, the negative sequence voltage $\left|V_{-t}^{m v}\right|$ can be approximately established using $\left|Z_{-+: t} I_{+: t}\right|$ for passive loads as indicated in IEC/TR $61000-3-13$ by (11).

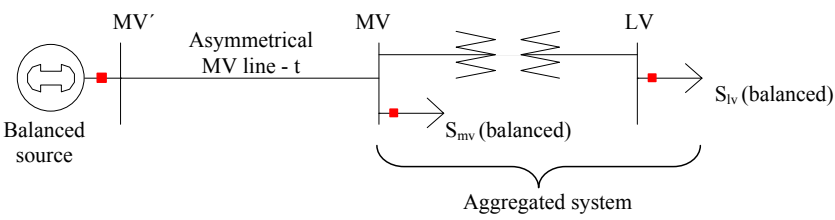

Fig. 7. MV-LV radial power system

Induction motor loads:

When the MV line supplies primarily three-phase induction motor loads at LV (ie. $S_{m v}=0$ ), the voltage $\left|V_{-t}^{m v}\right|$ can be expressed in terms of line, system and load characteristics and system operating conditions as:

$$
\left|V_{-t}^{m v}\right| \approx\left|Z_{-+: t} I_{+: t}\right| \frac{1}{1+\left(\frac{V R_{t}}{1-V R_{t}}\right)\left(\frac{1}{\frac{1}{k_{s}}+\frac{1}{k_{s c}}}\right)}
$$

where, $k_{s}$ and $k_{s c}$ are as defined in Section IV, however taking aggregated representation of the LV busbar into account.

Based on (14), the numerator (ie. $\left|Z_{-+: t} I_{+: t}\right|$ ) of (11) has to be further scaled down by the factor $\frac{1}{1+\left(\frac{V R_{t}}{1-V R_{t}}\right)\left(\frac{1}{\frac{1}{k_{s}}+\frac{1}{k_{s c}}}\right)}$ when the line supplies induction motor loads at LV. It is worthwhile noting that this reduction (eg. $40 \%$ with $k_{s c}^{l v}=20$, $k_{s}=6.7$ and $V R_{t}=10 \%$ ) is significant compared to that in relation to passive loads (eg. $10 \%$ with $V R_{t}=10 \%$ for constant impedance loads).

Fig. 8 illustrates the variation of $\left|V_{-t}^{m v}\right|$ with $\left|I_{+: t}\right|$ in relation to the four basic load types considered above established using (13) and (14) for a radial test system where $\left|Z_{-+: t}\right|=0.112 \Omega, k_{s c} \approx 20$ and $k_{s}=6.7$. This also shows the corresponding results obtained from unbalanced load flow analysis (LF) indicating that the new formulation is quite satisfactory for predicting the voltage $\left|V_{-t}^{m v}\right|$.

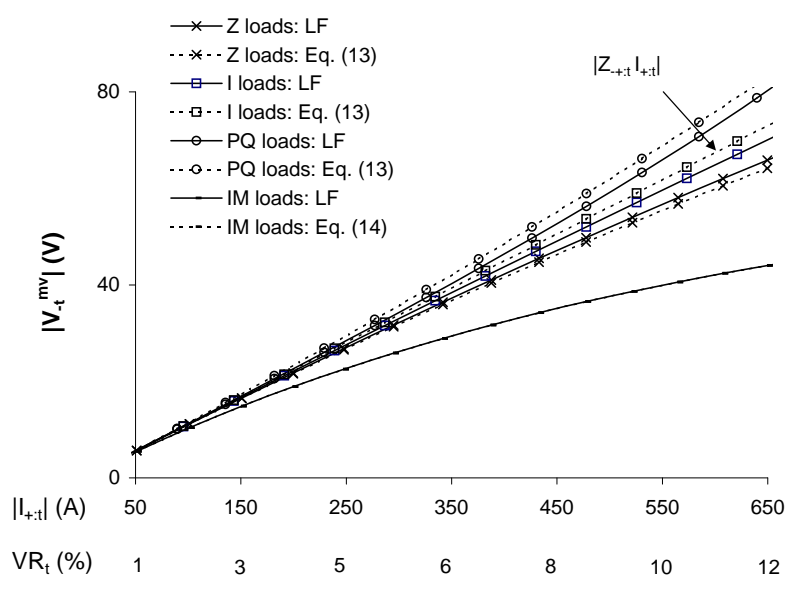

Fig. 8. Variation of $\left|V_{-t}^{m v}\right|$ with $\left|I_{+: t}\right|$ ( $V R_{t}$ values corresponding to various $\left|I_{+: t}\right|$ are also indicated) in relation to the four basic load types

In summary, it can be concluded that the level of influence 
of the negative sequence current (which arises due to the asymmetry of the MV line) on the voltage $\left|V_{-t}^{m v}\right|$ :

(a) is negligible in the presence of passive loads,

(b) is significant when the line supplies three-phase induction motor loads.

\section{Mix of passive and induction motor loads:}

When the MV line supplies a mix of passive loads (at busbars MV and LV) and induction motors (at busbar LV) the negative sequence voltage $\left|V_{-t}^{m v}\right|$ can be expressed as:

$$
\left|V_{-t}^{m v}\right| \approx\left|Z_{-+: t} I_{+: t}\right| \frac{1}{1+\left(\frac{V R_{t}}{1-V R_{t}}\right)\left(\frac{k_{l v}}{\frac{1}{k_{s} k_{m}}+\frac{1}{k_{s c}}}\right)}
$$

where,

$k_{m}$ - as defined in Section IV

$k_{l v}=\frac{S_{l v}}{S_{m v}+S_{l v}}$

The voltage unbalance $U_{t}^{m v}$ (as a VUF) can be expressed in a generalised form as:

$$
U_{t}^{m v} \approx \frac{\left|Z_{-+: t} I_{+: t}\right|}{1+\left(\frac{V R_{t}}{1-V R_{t}}\right)\left(\frac{k_{l v}}{\frac{1}{k_{s} k_{m}}+\frac{1}{k_{s c}}}\right)} \times \frac{1}{\left|V_{+}^{m v}\right|}
$$

where, $V_{+}^{m v}$ is the positive sequence voltage at busbar MV.

Fig. 9 illustrates the variation of $U_{t}^{m v}$ with $k_{m}$ established using (16) together with the results obtained from unbalanced load flow analysis for the radial test system considered above $\left(\left|Z_{-+: t}\right|=0.112 \Omega, k_{s c} \approx 20, k_{s}=6.7\right)$ in relation to three cases where:

(a) $k_{l v}=1$ (ie. $S_{m v}=0$ )

(b) $k_{l v}=0.5$

(c) $k_{l v}=0$ (ie. $S_{l v}=0, k_{m}=0$ )

The operating scenario considered corresponds to $\left|I_{+: t}\right| \approx$ $470 \mathrm{~A}, V R_{t} \approx 8.5 \%$ and $\left|V_{+}^{m v}\right| \approx 7.2 \mathrm{kV}(1 \mathrm{pu})$. These results clearly demonstrate that the direction given in IEC/TR 610003-13 by (11) is conservative when an MV line supplies a considerable proportion of induction motor loads.

\section{CONCLUSIONS}

The paper has summarised the basic concepts and the principles used in the Technical Report IEC/TR 61000-313 which is expected to provide the basis for developing an Australian Standard for voltage unbalance allocation. The propagation of voltage unbalance form MV to LV systems has been addressed proposing an improved methodology for its evaluation. Values greater than unity have been seen for the transfer coefficient in the presence of constant power loads, whereas the transfer coefficient is seen to be less than unity when the LV system supplies large proportions of three-phase induction motor loads. On the whole, the transfer coefficient is seen to vary approximately between 1.1 and 0.6 depending on the prevailing system conditions.

Further, the paper has addressed the global voltage unbalance in MV power systems which arise as a result of line asymmetries. The dependency of the global emission from line asymmetries on various load types including three-phase induction motor loads has been examined in relation to a radial asymmetrical MV line in detail. The direction given in IEC/TR 61000-3-13 to quantify the contribution to voltage unbalance by an asymmetrical line at its receiving end has been seen to be valid only when the line supplies primarily passive loads. In this case, the impact of the negative sequence current which arise as a result of the line asymmetry on the global emission is seen to be insignificant. However, the direction given in IEC/TR 61000-3-13 is seen to be conservative when the line supplies a large proportion of induction motor loads. In this case, the actual level of emission is lower that what is predicted by the direction given in IEC/TR 61000-3-13. This is seen to happen as a result of the significant impact of the negative sequence current on the emission which has not been taken into account in IEC/TR 61000-3-13.

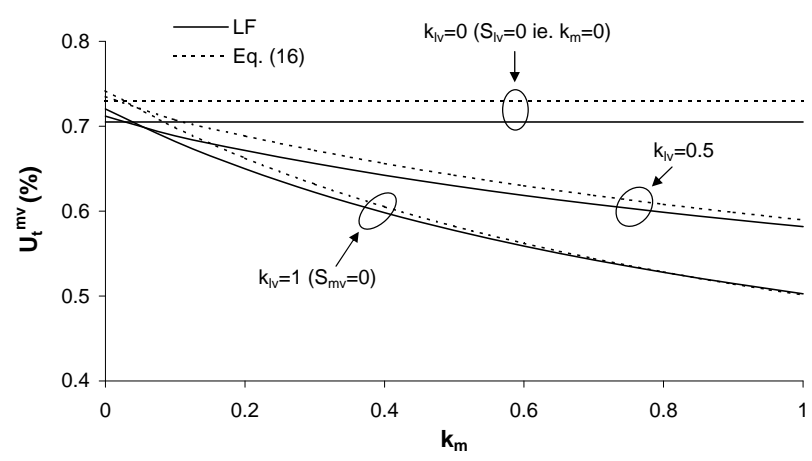

Fig. 9. Variation of $U_{t}^{m v}$ with $k_{m}$ for $k_{l v}=1, k_{l v}=0.5$ and $k_{l v}=0$

\section{REFERENCES}

[1] System Standards, National Electicity Code Australia, Version 1.0 Amendment 9.0, S5.1a.7, October 2004

[2] Electricity Distribution Code, Victoria, January 2002.

[3] Prabodha Paranavithana, Sarath Perera and Danny Sutanto, "Impact of Untransposed 66kV Sub-transmission Lines on Voltage Unbalance", Australasian Universities Power Engineering Conference, AUPEC, Paper 28, Melbourne-Australia, Dec. 2006.

[4] Prabodha Paranavithana, Sarath Perera and Danny Sutanto, "Analysis of System Asymmetry of Interconnected 66kV Sub-transmission Systems in relation to Voltage Unbalance", IEEE PES PowerAfrica 2007 Conference and Exposition, Paper 35, Johannesburg-South Africa, 16-20 July 2007.

[5] "Electromagnetic Compatibility (EMC) - Limits - Assessment of Emission Limits for the Connection of Unbalanced Installations to MV, HV and EHV Power Systems", IEC Technical Report 61000-3-13, Ed. 1, 2008.

[6] "Electromagnetic Compatibility (EMC) - Limits - Assessment of Emission Limits for Distorting Loads in MV and HV Power Systems", AS/NZS 61000-3-6, 2001.

[7] "Electromagnetic Compatibility (EMC) - Limits - Assessment of Emission Limits for Distorting Loads in MV and HV Power Systems", IEC Technical Report 61000-3-6, Ed. 1, 1996.

[8] "Electromagnetic Compatibility (EMC) - Limits - Assessment of Emission Limits for Fluctuating Loads in MV and HV Power Systems", AS/NZS 61000-3-7, 2001.

[9] "Electromagnetic Compatibility (EMC) - Limits - Assessment of Emission Limits for Fluctuating Loads in MV and HV Power Systems", IEC Technical Report 61000-3-7, Ed. 1, 1996.

[10] Robert Koch, Germain Beaulieu, Luc Berthet and Mark Halpin "International Survey of Unbalance Levels in LV, MV, HV and EHV Power Systems: CIGRE/CIRED JWG C4.103 Results", 19th International Conferance on Electricity Distribution, paper 0892, Vienna, 21-24 May 2007. 